\title{
Close to recommended caloric and protein intake by enteral nutrition is associated with better clinical outcome of critically ill septic patients: secondary analysis of a large international nutrition database
}

\author{
Gunnar Elke ${ }^{1}$, Miao Wang ${ }^{2}$, Norbert Weiler ${ }^{1}$, Andrew G Day ${ }^{2}$ and Daren K Heyland²*
}

\begin{abstract}
Introduction: Current international sepsis guidelines recommend low-dose enteral nutrition (EN) for the first week. This contradicts other nutrition guidelines for heterogenous groups of ICU patients. Data on the optimal dose of EN in septic patients are lacking. Our aim was to evaluate the effect of energy and protein amount given by EN on clinical outcomes in a large cohort of critically ill septic patients.

Methods: We conducted a secondary analysis of pooled data collected prospectively from international nutrition studies. Eligible patients had a diagnosis of sepsis and/or pneumonia and were admitted to the ICU for $\geq 3$ days, mechanically ventilated within 48 hours of ICU admission and only receiving EN. Patients receiving parenteral nutrition were excluded. Data were collected from ICU admission up to a maximum of 12 days. Regression models were used to examine the impact of calorie and protein intake on 60-day mortality and ventilator-free days.

Results: Of the 13,630 patients included in the dataset, 2,270 met the study inclusion criteria. Patients received a mean amount of $1,057 \mathrm{kcal} / \mathrm{d}(14.5 \mathrm{kcal} / \mathrm{kg} /$ day $)$ and $49 \mathrm{~g}$ protein/day $(0.7 \mathrm{~g} / \mathrm{kg} / \mathrm{d})$ by EN alone. Patients were mechanically ventilated for a median of 8.4 days and 60 -day mortality was $30.5 \%$. An increase of 1,000 kcal was associated with reduced 60 -day mortality (odds ratio (OR) $0.61 ; 95 \%$ confidence interval (CI) 0.48 to $0.77, P<0.001$ ) and more ventilator-free days ( 2.81 days, $95 \% \mathrm{Cl} 0.53$ to $5.08, P=0.02$ ) as was an increase of $30 \mathrm{~g}$ protein per day (OR 0.76; $95 \% \mathrm{Cl} 0.65$ to $0.87, P<0.001$ and 1.92 days, $95 \% \mathrm{Cl} 0.58$ to $3.27, P=0.005$, respectively).

Conclusions: In critically ill septic patients, a calorie and protein delivery closer to recommended amounts by EN in the early phase of ICU stay was associated with a more favorable outcome.
\end{abstract}

\section{Introduction}

Critically ill patients are characterized by marked variations in energy requirements $[1,2]$ and net protein catabolism due to disproportional cytokine and stress hormone release [3-5]. These patients are prone to develop energy and protein deficits over their time of ICU stay, as they are unable to resume oral feeds. To prevent adverse outcomes related to nutritional deficits such as increased

\footnotetext{
* Correspondence: dkh2@queensu.ca

${ }^{2}$ Clinical Evaluation Research Unit, Kingston General Hospital, Angada 4, K7L 2V7, Kingston, ON, Canada

Full list of author information is available at the end of the article
}

infectious complications, nutritional support is warranted [6-8]. Current guidelines uniformly recommend enteral nutrition (EN) as first-line therapy, starting early within 24 to 48 hours after ICU admission [9-11]. Early EN has thereby several non-nutritional benefits such as supporting the immune and metabolic responses as well as preserving gut integrity [12]. However, it is still less clear what the optimal dose of EN should be, particularly during the first week of illness, and how specific subgroups of critically ill patients respond to the amount of energy and protein delivered by EN.

\section{Biomed Central}

(c) 2014 Elke et al.; licensee BioMed Central Ltd. This is an Open Access article distributed under the terms of the Creative Commons Attribution License (http://creativecommons.org/licenses/by/2.0), which permits unrestricted use, distribution, and reproduction in any medium, provided the original work is properly credited. 
Three recent large studies [13-15] have compared full enteral feeding to intentional underfeeding or trophic nutrition, that is provision of small volume EN aiming to produce positive local effects on gastrointestinal mucosa and beneficial systemic effects [16]. None of these studies showed an effect on mortality [13-15]. Based on these studies, the updated Surviving Sepsis Campaign guidelines [17] suggest to avoid mandatory full caloric feeding but use low-dose enteral feeding in the first week of ICU stay (evidence grade 2B). This contradicts the 2013 Canadian critical care nutrition guidelines that recommend optimizing the dose of EN and not using an initial strategy of trophic feeds for five days [18] based on randomized but also large-scale observational studies in heterogeneous critically ill patients [19-22].

Given the paucity of prospective randomized clinical trials in septic patients and in view of the contradictory recommendations, we conducted a secondary analysis of a large international nutrition database. The aim was to evaluate the effect of energy and protein intake given by EN on clinical outcomes in a large cohort of critically ill septic patients receiving only EN. We hypothesized that EN delivery of calories and protein closer to recommended amounts in the early phase of critical illness would be associated with increased survival and ventilator-free days.

\section{Material and methods}

\section{Study design and patients}

This retrospective study was a secondary analysis of pooled data from the International Nutrition Survey (INS) and baseline data from the Enhanced ProteinEnergy Provision via the Enteral Route in Critically Ill Patients (PEP uP) study [23,24]. Data were prospectively collected from 737 ICUs in 33 countries annually during five study periods between 2007 and 2011. Institutional ethics approval was obtained from the Health Sciences Research Ethics Board at Queen's University, Kingston, $\mathrm{ON}$ as the responsible ethics committee and all other participating sites were advised and agreed to contact their local institutional ethics boards regarding the necessity of ethics approval for study participation. The need for informed patient consent was waived given the nature of the studies (for PEP uP: a system-level quality improvement study and INS: an observational survey).

Details of the study design, data collection and management were described previously $[23,24]$. In these studies, critically ill adult patients who were mechanically ventilated within the first 48 hours of ICU admission and with an ICU stay more than three days were enrolled. This a priori removed potentially confounding patients that have short stays in ICU (less than three days), receive little EN, and universally have a good outcome [25]. The current analysis was restricted to those critically ill adult patients with an ICU admission diagnosis of sepsis and pneumonia, given that mechanically ventilated patients admitted with pneumonia are most often septic [26,27]. The Acute Physiology and Chronic Health Evaluation II (APACHE II) admission diagnosis taxonomy was used to codify the admission diagnosis. This case determination was not adjudicated but abstracted from a chart by the health-care professional responsible for collecting the data of the concerned nutrition study. In addition, only those patients who were receiving exclusively EN were included. We thereby intended to preclude possible confounding effects of parenteral nutrition (PN) on the amount of nutrition as PN has a treatment effect different and distinct from EN [28-30]. Site characteristics, patients' baseline demographic and physiologic data, and severity of illness were collected at the time of study enrollment. Daily information on nutrition therapy including the amount of nutrition received by EN (calories and protein), morning serum glucose levels, and use of promotility drugs were collected daily for a maximum of 12 days or until death or ICU discharge. Nutrition therapy was left at the discretion of each site investigator as no studyspecific standardized nutrition protocol was followed.

ICU and hospital outcomes, including ventilation status, length of ICU and hospital stays, and mortality, were determined from hospital records at 60 days after ICU admission.

\section{Statistical analysis}

Site characteristics are presented as means and ranges or counts and percentages. Patient characteristics, nutritional variables and clinical outcomes are presented as counts and percentages for categorical variables, medians and quartiles for ventilator-free days and length of stay variables, and means and standard deviations for other continuous variables.

Nutrition adequacy was defined as the total amount of energy or protein received from EN over the first 12 ICU days divided by the amount prescribed at baseline and expressed as a percentage. Days after permanent progression to exclusive oral feeding were excluded, but days without EN prior to exclusive oral feeding were counted as 0 .

Logistic and linear regression with random intercepts to account for within ICU dependence were used to associate mortality and ventilator-free days respectively to energy and protein (in separate models) received during the first 12 ICU days prior to death or permanent switch to exclusive oral feeding. Energy and protein were modeled separately due to their high co-linearity. The models were run without adjustment and adjusting for days with nutrition, body mass index (BMI), age and APACHE score. In accordance with a previous publication [23], we report the odds of 60-day mortality and the expected mean change in ventilator-free days separately per increase of 
$1,000 \mathrm{kcal}$ and $30 \mathrm{~g}$ of protein, respectively. In order to aid in the interpretability of these models, we report the relationship between nutritional intake and 60-day mortality by dividing patients into groups of tertiles based on the amounts of energy and protein received and using regression techniques to describe subsequent effect on outcome. This tertile grouping (based on distribution of intake) is consistent with what previous investigators have published in the literature [25,31]. In addition, we performed a sensitivity analysis to examine the association between EN intake during only the first seven days of ICU stay and subsequent outcome in a subset of patients. To be eligible for this analysis, patients had to receive at least seven days of EN and be alive for subsequent assessment of mortality. Patients who died before day seven or who were transferred out of ICU or transition to oral feeds prior to day seven were excluded from this sensitivity analysis. This selection strategy better separating exposure (nutrition intake in the first seven days) from outcome assessment (subsequent mortality) is consistent with the time period (first seven days) the Surviving Sepsis campaign guidelines [17] refer to.

Statistical analyses were performed using SAS software, version 9.2 (SAS Institute, Cary, NC, USA).

\section{Results}

\section{Site and patient characteristics}

A detailed flowchart showing the flow of patients in this analysis is given in Figure 1. Of 13,630 patients enrolled in the surveys, 2,270 patients from 351 ICUs were included in the current analysis. Forty-five percent of these patients had sepsis and 55\% had pneumonia. The majority of ICUs (77.8\%) had an implemented feeding protocol including a protocol for glycemic control as well as dietitian(s) present (84.1\%) (Table A1 in Additional file 1). The mean age of the patients was 61.7 years, $56.3 \%$ were male and mean BMI was 27.6. Nearly half of the patients $(45.9 \%)$ had a BMI below $25 \mathrm{~kg} / \mathrm{m}^{2}$. Mean APACHE II score was 23.9 (Table 1).

\section{Nutrition therapy}

Comprehensive information on nutrition therapy is described in Table 2. On average, EN was started within 48 hours (mean \pm standard deviation (SD) $26.6 \pm 26.4$ hours from admission to ICU). Overall, study patients received a mean energy of $1,057 \pm 480 \mathrm{kcal} /$ day $(14.5 \pm 7.2 \mathrm{kcal} / \mathrm{kg} /$ day) resulting in $61 \%$ adequacy of calories from prescribed EN. Mean protein intake was $49 \pm 24 \mathrm{~g} /$ day $(0.7 \pm 0.3 \mathrm{~g} / \mathrm{kg} /$ day), representing $57 \%$ adequacy of protein prescription. The progression of calories and protein by EN over the first 12 ICU days is shown in Figure A1 in Additional file 2. The weight-based formula was found to be the most frequent method to calculate energy requirements while indirect calorimetry was only rarely used. The actual body weight was predominantly used for calculation of nutrition prescription (50.4\% of patients). Mean morning serum glucose level was $7.9 \mathrm{mmol} / \mathrm{l}$. In 451 patients who ever had EN interrupted due to high gastric residual volumes, motility agents were used in $68.1 \%$ of these patients while only $12.6 \%$ received small bowel feeding. Argininesupplemented and fish oil-supplemented formulas were used in only $3.5 \%$ and $6.3 \%$ of study patients, respectively (Table 2).

\section{Outcomes}

Clinical outcomes of the whole study patient population are shown in Table 1 and the outcomes of the patients included in the sensitivity analysis are shown in Table A2 in Additional file 1. In the whole population, overall mortality was $30.5 \%$ at 60 days. Median length of mechanical ventilation was 8.4 days with a length of stay in the ICU of 11.5 days. Table 3 and Table A3 in Additional file 1 present the relationship between increased nutrition and mortality or ventilator-free days, respectively, for both the entire study population and the sensitivity analysis. Both adjusted and unadjusted analyses revealed that the provision of each additional 1,000 kcal per day was associated with significant reduction in 60-day mortality (adjusted odds ratio (OR) 0.61, 95\% confidence interval (CI) 0.48 to 0.77 ) and an increase in ventilator-free days (adjusted 2.81 days, 95\% CI 0.53 to 5.08) as was the provision of additional $30 \mathrm{~g}$ protein per day (adjusted OR 0.76, 95\% CI 0.65 to 0.87 and 1.92 days, 95\% CI 0.58 to 3.27 , respectively). The 60 -day mortality results remained virtually unchanged when we estimated the effect of only the first seven days of EN on subsequent mortality among patients who were alive and evaluable for nutritional support for at least seven days. However, the positive effect on ventilator-free days only remained statistically significant with an increased protein but not caloric intake (see Table A3 in Additional file 1). In addition, Table A4 in Additional file 1 shows that the lowest tertile of energy and protein intake received per day (patients receiving $\leq 865 \mathrm{kcal} / \mathrm{d}$ and $\leq 39.5 \mathrm{~g} / \mathrm{d}$, respectively) was associated with increased 60-day mortality as compared to the highest tertile (patients receiving $\geq 1,294 \mathrm{kcal} / \mathrm{d}$ and $\geq 58.9 \mathrm{~g} / \mathrm{d}$, respectively).

\section{Discussion}

This secondary analysis of a large nutrition database included 2,270 patients with sepsis and pneumonia with an ICU length of stay $\geq 3$ days. The analysis was deliberately restricted to patients receiving EN alone to avoid the possible confounding effect of $\mathrm{PN}$ and specifically address the relationship between the amount of EN and outcome. The main finding was that an increased amount of calories and protein per day during the early phase of ICU stay was associated with lower 60-day 


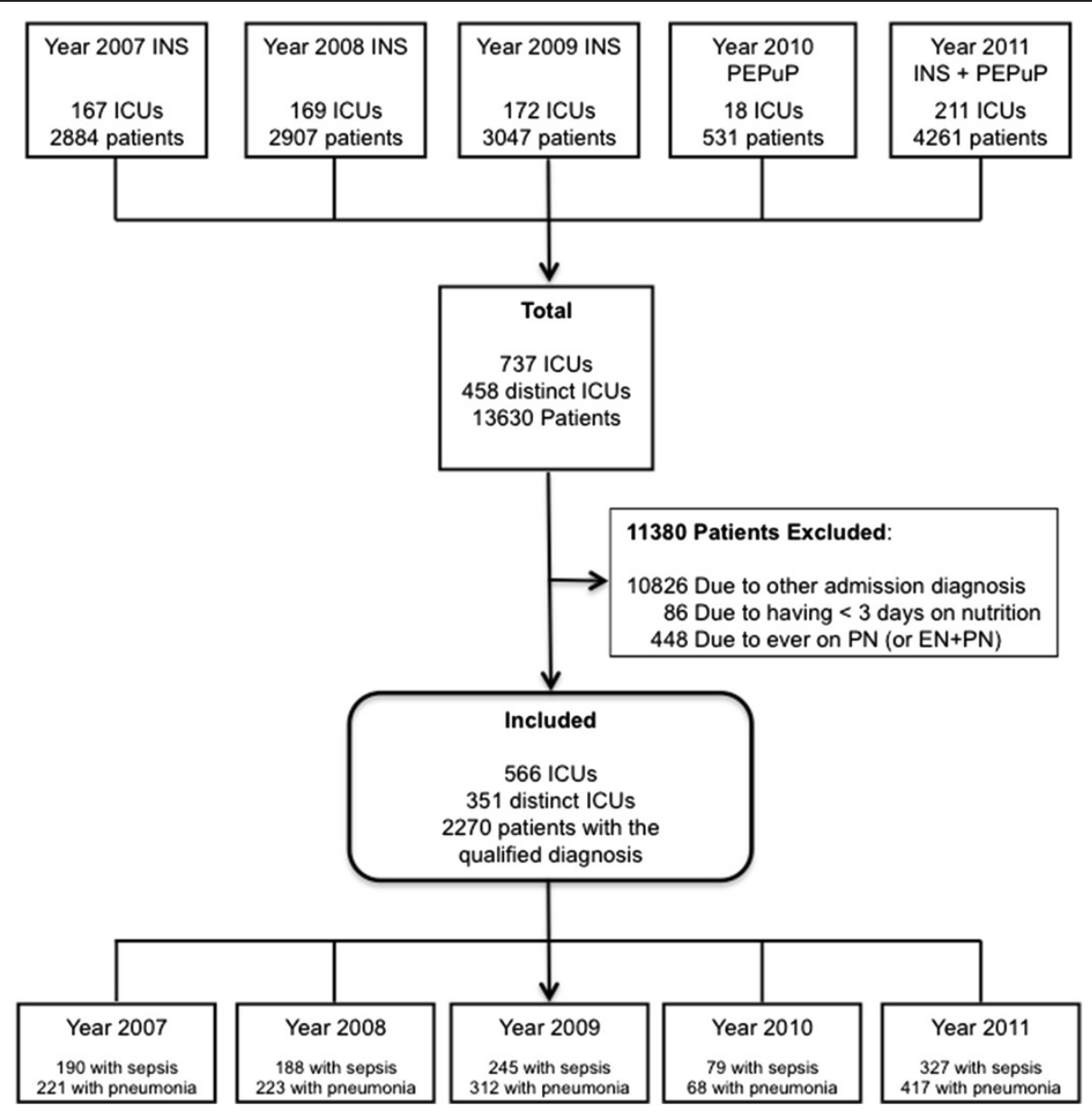

Figure 1 Flow chart of study population. Of 13,630 patients enrolled in the nutrition surveys and PEP uP trial between 2007 and $2011,2,270$ patients with pneumonia and sepsis from 351 ICUs were included in the final analysis. The 411 patients from the 2007 database were already included in a previous study [23]. EN, enteral nutrition; ICU, intensive care unit; INS, International Nutrition Survey; PN, parenteral nutrition.

mortality and an increase in ventilator-free days. Our findings should not be interpreted that we recommend overfeeding but rather, that the amount of calories and protein better approximates that which was prescribed.

Our results are in contrast to the findings from three recent prospective randomized studies that compared full enteral feeding to intentional underfeeding or trophic nutrition and did not show a significant mortality difference [13-15]. Two most recently published follow-up analyses of the largest, the so-called EDEN trial revealed no differences in long-term physical or cognitive outcomes six and twelve months after initial trophic or full enteral feeding [32,33]. Based on these studies, the updated Surviving Sepsis Campaign guidelines suggest to avoid full caloric feeding and use low-dose enteral feeding in the first week of ICU stay (evidence grade 2B) [17]. Perhaps the differences between these studies and our analysis could be explained by the differences in patient populations studied. The study by Arabi et al. [13] only included a limited number of septic patients (72 of a total of 240 patients). The EDEN trial [15] included a selected sample of patients with acute lung injury that were relatively young (mean age 52 years), well-nourished and fairly obese (average BMI of around 30) whereas our population was older (average age 62 years) and almost half of the patients had a low to normal BMI. In a prior analysis, Alberda and colleagues [23] demonstrated that patients with a BMI from 25 to 35 may not be sensitive to differing amounts of $\mathrm{EN}$, at least with respect to mortality, whereas a mortality reduction was associated with receiving more $\mathrm{EN}$ in patients with BMI $<25$ and $>35$. A further point is that the average duration of ICU stay in the EDEN study was five days compared to eleven days in our study. To the extent that early targeted EN is particularly relevant in patients with longer length of stay $[34,35]$, this may further explain the discordant results. All of these observations and explanations lead us to question the generalizability of the EDEN study [15] to practice, which is best represented by our study population reflecting a more heterogenous septic population representative of real-life settings. 


$\begin{aligned} & \text { Table } \mathbf{1} \text { Characteristics and clinical outcomes of study } \\
& \text { patients }\end{aligned}$
\begin{tabular}{ll}
\hline Number of patients & Total \\
\cline { 2 - 2 } $\mathbf{n = 2 , 2 7 0}$ \\
\hline Age, years (SD) & $61.7(17.0)$ \\
Sex, male (\%) & $1,277(56.3)$ \\
Height, metres (SD) & $1.68(0.11)$ \\
Weight, kg (SD) & $78.1(26.0)$ \\
BMl, mean (SD) & $27.6(8.3)$ \\
BMl, n (\%) & \\
$<24$ & $1,039(45.9)$ \\
$25-29$ & $594(26.2)$ \\
$30-40$ & $463(20.4)$ \\
$>40$ & $169(7.5)$
\end{tabular}

Admission type

Medical, n (\%)

$2,270(100)$

Surgical

ICU admission diagnosis, n (\%)

Aspiration pneumonia

Bacterial/viral pneumonia

Sepsis (other than urinary tract)

Sepsis of urinary tract origin

0

330 (14.5)

$911(40.1)$

859 (37.8)

$170(7.5)$

$23.9(7.9)$

APACHE II score, mean (SD)

$6.55[0.08,65.08]$ (hours), median [IQR]

Days from hospital admission to ICU admission, $\mathrm{n}$ (\%)

$$
\begin{aligned}
& \text { [0-1] day } \\
& \text { [1-3] days } \\
& >3 \text { days }
\end{aligned}
$$

$1,437(63.4)$
$303(13.4)$
$527(23.3)$
$11.5[6.9-21.4]$
$23.8[13.8-48.5]$
$8.4[4.6-19.2]$
$46.4[4.0-55.0]$
30.5

Length of ICU stay (days), median [IQR]

Length of hospital stay (days), median [IQR]

Length of mechanical ventilation (days), median [IQR]

Ventilator-free days, median [IQR]

30.5

Length of ICU stay, hospital stay and mechanical ventilation were based on 60-day survivors only. SD, standard deviation; BMI, body mass index; ICU, intensive care unit; APACHE II, Acute Physiology and Chronic Health Evaluation II; IQR, interquartile range.

Our findings are consistent with the Canadian clinical practices guidelines that do not recommend trophic feeds or intentional undernourishment [18], which are based on prospective randomized but also large observational trials in other, non-septic patients. Two of these were randomized controlled studies showing that patients with enhanced enteral feeding had subsequent decreased infection, hospital length of stay, and a trend toward reduced mortality, respectively, compared to patients receiving standard nutrition with lower amounts of

\begin{tabular}{|c|c|}
\hline \multirow[t]{2}{*}{ Number of patients } & \multirow{2}{*}{$\frac{\text { Total }}{n=2,270}$} \\
\hline & \\
\hline \multicolumn{2}{|l|}{ Nutritional prescription } \\
\hline Mean energy, kcal/day (SD) & $1,757.7(352.1)$ \\
\hline Mean energy, kcal/kg/day (SD) & $23.9(5.7)$ \\
\hline Mean protein, gram/day (SD) & $88.2(24.7)$ \\
\hline Mean protein, gram/kg/day (SD) & $1.2(0.3)$ \\
\hline \multicolumn{2}{|l|}{ Nutrition received } \\
\hline Mean energy, kcal/day (SD) & $1,056.9(480.5)$ \\
\hline Mean energy, kcal/kg/day (SD) & $14.5(7.2)$ \\
\hline Adequacy of calories from nutrition therapy, \% (SD) & $60.8(26.3)$ \\
\hline Mean protein, gram/day (SD) & $48.9(24.3)$ \\
\hline Mean protein, gram/kg/day (SD) & $0.7(0.3)$ \\
\hline Adequacy of protein from nutrition therapy, \% (SD) & $57.0(26.6)$ \\
\hline \multicolumn{2}{|l|}{ Number of patients on nutrition therapy, $\mathrm{n}(\%)$} \\
\hline EN only & $2,204(97.1)$ \\
\hline None & $66(2.9)$ \\
\hline Hours to initiation of EN mean (SD) & $26.6(26.4)$ \\
\hline Mean morning blood glucose (mmol/l) (SD) & $7.9(1.9)$ \\
\hline Head of elevation & $32.7(9.9)$ \\
\hline Motility agent use in patients with EN intolerance*, n (\%) & $307(68.1)$ \\
\hline Small bowel feeding in patients with EN intolerance*, n (\%) & $57(12.6)$ \\
\hline \multicolumn{2}{|l|}{ EN formula, n (\%) } \\
\hline Arginine-enriched formula & $79(3.5)$ \\
\hline Fish oil-enriched formula & $143(6.3)$ \\
\hline Glutamine-enriched formula & $5(0.2)$ \\
\hline Polymeric formula & $1,976(87.1)$ \\
\hline
\end{tabular}
nutrition [21,22]. Two observational studies, one in 207
Table 2 Nutrition data of study patients

Body weight used in calculation of nutrition prescription, n (\%)

Actual body weight

$1,144(50.4)$

IBW based on Hamwi formula

$117(5.2)$

IBW based on BMI $20-25 \mathrm{~kg} / \mathrm{m}^{2}$

$254(11.2)$

Other

$691(30.4)$

No weight used in calculation

$18(0.8)$

Missing

$46(2.0)$

Method used to calculate energy requirements ${ }^{\#}, \mathrm{n}(\%)$

$\begin{array}{ll}\text { Indirect calorimetry } & 13(0.6) \\ \text { Harris-Benedict equation } & 259(11.4) \\ \text { Weight-based formula } & 1,220(53.7) \\ \text { Other }^{\S} & 854(37.6) \\ \text { None } & 8(0.4)\end{array}$

*Among 451 patients who were ever on EN and ever had feeds interrupted due to high gastric residual volumes; "sum of patient numbers within this category may be higher than total column patient number since one patient could contribute to multiple methods in the PEPuP and INS 2011 studies; ${ }^{\S}$ other includes Schofield with/without adjustment for stress and activity, Ireton-Jones, Mifflin-St. Jeor equation and fixed calorie target. kcal, kilocalories; SD, standard deviation; EN, enteral nutrition; IBW, ideal body weight; BMI, body mass index. 
Table 3 Relationship between enteral nutrition and 60-day mortality

\begin{tabular}{|c|c|c|c|c|c|c|}
\hline & \multicolumn{3}{|c|}{ Unadjusted } & \multicolumn{3}{|c|}{ Adjusted } \\
\hline & Odds ratio & $95 \% \mathrm{Cl}$ & $P$ value & Odds ratio & $95 \% \mathrm{Cl}$ & $P$ value \\
\hline \multicolumn{7}{|c|}{ A: Total study population $(n=2,270)$} \\
\hline \multicolumn{7}{|l|}{ Energy intake } \\
\hline Per $1,000 \mathrm{kcal}$ & 0.51 & $(0.41-0.64)$ & $<0.001$ & 0.61 & $(0.48-0.77)$ & $<0.001$ \\
\hline \multicolumn{7}{|l|}{ Protein intake } \\
\hline Per 30 gram & 0.70 & $(0.61-0.80)$ & $<0.001$ & 0.76 & $(0.65-0.87)$ & $<0.001$ \\
\hline \multicolumn{7}{|c|}{ B: Sensitivity analysis $(n=1,560)$} \\
\hline \multicolumn{7}{|l|}{ Energy intake } \\
\hline Per $1,000 \mathrm{kcal}$ & 0.56 & $(0.44-0.71)$ & $<0.001$ & 0.61 & $(0.48-0.79)$ & $<0.001$ \\
\hline \multicolumn{7}{|l|}{ Protein intake } \\
\hline Per 30 gram & 0.72 & $(0.62-0.83)$ & $<0.001$ & 0.75 & $(0.64-0.87)$ & $<0.001$ \\
\hline
\end{tabular}

medical-surgical ICU patients [36] and the other in 103 critically ill patients with burns [37] consistently showed that those who enterally received greater amounts of energy and protein had significantly lower infectious morbidity or mortality, respectively. Randomized controlled trials are considered to represent most valid evidence to inform clinical guidelines. However, for many reasons, as outlined by Vincent [38] they cannot persistently provide conclusive answers. Evidence from well-conducted cohort studies may provide additional relevant and valid information $[39,40]$ and should be taken into account for clinical guideline implementation, as they are closer to the real daily nutritional practice in the ICU setting [41].

In this respect, the major strength of our study is the large number of septic patients enrolled from multiple, international ICUs, which is to our knowledge the largest report on nutrition therapy in this critically ill patient population. Observing the same signals as Alberda et al. [23], who included all patients admitted to the ICU not just septic patients, and given the large and heterogenous group of critically ill septic patients from many sites. enhances the likelihood that our data are valid. The statistical analysis used was robust by adjusting for timing, length of nutrition and ICU stay as well as severity of illness. We thereby avoided a potential bias of incorrect adjustment for patients with short ICU stays that receive very little nutrition and typically have a very good outcome. The inability or inadequate nature of adjusting for these low-risk patients is largely the reason why some studies show that better fed patients have worse clinical outcomes [25]. We also used a sensitivity analysis to examine the association between nutritional intake during the first seven ICU days and outcome.

Admittedly, our results should still be interpreted with caution and viewed as hypothesis generating given the pooled observational nature of the study. Thus, the link between better delivery of calories and protein (providing closer to recommended amounts) and better outcomes may not be a causal relationship. It could be that less sick patients tolerate their nutrition better and independently have a better clinical outcome. Furthermore, we are unable to categorize our patients with respect to the level of sepsis (severe sepsis or septic shock) because these data to grade severity of illness were not collected in our dataset. A further limitation is that our results are not generalizable to surgical critically ill patients with sepsis as only medical patients were represented in our study.

\section{Conclusions}

In conclusion, our study showed that a closer to recommended EN intake (that is calories and protein) given during the early phase of ICU stay was associated with a more favorable outcome in critically ill septic patients. These findings disagree with three recent prospective randomized trials on which the current Surviving Sepsis Campaign guidelines base their recommendation to use low-dose rather than full enteral feeding in septic patients. Further large trials are warranted based on our hypothesis-generating results that septic patients at high nutrition risk benefit from early increased EN.

\section{Key messages}

- A daily calorie and protein delivery closer to recommended amounts by EN within the early phase of ICU stay was associated with shorter duration of mechanical ventilation and lower mortality in septic patients.

- These findings challenge the current Surviving Sepsis Campaign guidelines that recommend the use of lowdose rather than full enteral feeding in septic patients. 
- Further large trials are warranted based on these hypothesis-generating results that septic patients at high nutrition risk benefit from early increased EN.

\section{Additional files}

Additional file 1: Table A1. Characteristics of participating ICUs. Table A2. Clinical outcomes of patients included in the sensitivity analysis. Table A3. Relationship between enteral nutrition and ventilator-free days. Table A4. Relationship between enteral nutrition (tertile groups) and 60-day mortality).

Additional file 2: Progression of calories and protein by enteral nutrition.

\section{Abbreviations}

APACHE II: Acute Physiology and Chronic Health Evaluation II; BMI: body mass index; Cl: confidence interval; EN: enteral nutrition; IBW: ideal body weight; ICU: intensive care unit; INS: International Nutrition Survey; kcal: kilocalories; OR: odds ratio; PN: parenteral nutrition; SD: standard deviation.

\section{Competing interests}

GE has received speaker's honoraria from Abbott, B Braun, and Fresenius Kabi. DKH has received research grants and speaker honorarium from Fresenius Kabi, Baxter, and Biosyn. All other authors declare that they have no competing interests.

\section{Authors' contributions}

GE and DKH conceived the study and drafted the manuscript. DKH, MW and AGD performed the statistical analysis. GE, MW, NW, AGD and DKH participated in the analysis and interpretation of data and revision of the manuscript. All authors read and approved the final manuscript.

\section{Author details}

'Department of Anaesthesiology and Intensive Care Medicine, University Medical Centre Schleswig-Holstein, Campus Kiel, Arnold-Heller-Strasse 3 Haus 12, 24105 Kiel, Germany. ${ }^{2}$ Clinical Evaluation Research Unit, Kingston General Hospital, Angada 4, K7L 2V7, Kingston, ON, Canada.

Received: 31 May 2013 Accepted: 23 January 2014

Published: 10 February 2014

\section{References}

1. Fontaine $\mathrm{E}$, Muller MJ: Adaptive alterations in metabolism: practical consequences on energy requirements in the severely ill patient. Curr Opin Clin Nutr Metab Care 2011, 14:171-175.

2. Zauner C, Schuster Bl, Schneeweiss B: Similar metabolic responses to standardized total parenteral nutrition of septic and nonseptic critically ill patients. Am J Clin Nutr 2001, 74:265-270.

3. Hoffer $L$, Bistrian BR: Why critically ill patients are protein deprived. JPEN J Parenter Enteral Nutr 2013, 37:300-309.

4. Lightfoot A, McArdle A, Griffiths RD: Muscle in defense. Crit Care Med 2009, 37:S384-S390

5. Soeters PB, Grimble RF: Dangers, and benefits of the cytokine mediated response to injury and infection. Clin Nutr 2009, 28:583-596.

6. Correia MI, Waitzberg DL: The impact of malnutrition on morbidity, mortality, length of hospital stay and costs evaluated through a multivariate model analysis. Clin Nutr 2003, 22:235-239.

7. Jensen GL, Mirtallo J, Compher C, Dhaliwal R, Forbes A, Grijalba RF, Hardy G, Kondrup J, Labadarios D, Nyulasi I, Castillo Pineda JC, Waitzberg D: Adult starvation and disease-related malnutrition: a proposal for etiology-based diagnosis in the clinical practice setting from the International Consensus Guideline Committee. JPEN J Parenter Enteral Nutr 2010, 34:156-159.

8. Middleton MH, Nazarenko G, Nivison-Smith I, Smerdely P: Prevalence of malnutrition and 12-month incidence of mortality in two Sydney teaching hospitals. Intern Med J 2001, 31:455-461.

9. Heyland DK, Dhaliwal R, Drover JW, Gramlich L, Dodek P: Canadian clinical practice guidelines for nutrition support in mechanically ventilated, critically ill adult patients. JPEN J Parenter Enteral Nutr 2003, 27:355-373.
10. McClave SA, Martindale RG, Vanek WW, McCarthy M, Roberts P, Taylor B, Ochoa JB, Napolitano L, Cresci G: Guidelines for the provision and assessment of nutrition support therapy in the adult critically ill patient: Society of Critical Care Medicine (SCCM) and American Society for Parenteral and Enteral Nutrition (A.S.P.E.N.). JPEN J Parenter Enteral Nutr 2009, 33:277-316.

11. Singer $P$, Berger MM, Van den Berghe G, Biolo G, Calder P, Forbes $A$, Griffiths R, Kreyman G, Leverve X, Pichard C: ESPEN: ESPEN guidelines on parenteral nutrition: intensive care. Clin Nutr 2009, 28:387-400.

12. McClave SA, Heyland DK: The physiologic response and associated clinical benefits from provision of early enteral nutrition. Nutr Clin Pract 2009, 24:305-315.

13. Arabi YM, Tamim HM, Dhar GS, Al-Dawood A, Al-Sultan M, Sakkijha MH, Kahoul SH, Brits R: Permissive underfeeding and intensive insulin therapy in critically ill patients: a randomized controlled trial. Am J Clin Nutr 2011, 93:569-577.

14. Rice TW, Mogan S, Hays MA, Bernard GR, Jensen GL, Wheeler AP: Randomized trial of initial trophic versus full-energy enteral nutrition in mechanically ventilated patients with acute respiratory failure. Crit Care Med 2011, 39:967-974.

15. Rice TW, Wheeler AP, Thompson BT, Steingrub J, Hite RD, Moss M, Morris A, Dong N, Rock P: Initial trophic vs full enteral feeding in patients with acute lung injury: the EDEN randomized trial. JAMA 2012, 307:795-803.

16. Sondheimer JM: A critical perspective on trophic feeding. J Pediatr Gastroenterol Nutr 2004, 38:237-238.

17. Dellinger RP, Levy MM, Rhodes A, Annane D, Gerlach H, Opal SM, Sevransky JE, Sprung CL, Douglas IS, Jaeschke R, Osborn TM, Nunnally ME, Townsend SR, Reinhart K, Kleinpell RM, Angus DC, Deutschman CS, Machado FR, Rubenfeld GD, Webb SA, Beale RJ, Vincent JL, Moreno R: Surviving sepsis campaign: international guidelines for management of severe sepsis and septic shock: 2012. Crit Care Med 2013, 41:580-637.

18. Dhaliwal R, Cahill N, Lemieux M, Heyland DK: The canadian critical care nutrition guidelines in 2013: an update on current recommendations and implementation strategies. Nutr Clin Pract 2014, 29:29-43.

19. Desachy A, Clavel M, Vuagnat A, Normand S, Gissot V, Francois B: Initial efficacy and tolerability of early enteral nutrition with immediate or gradual introduction in intubated patients. Intensive Care Med 2008, 34:1054-1059.

20. Doig GS, Simpson F, Finfer S, Delaney A, Davies AR, Mitchell I, Dobb G: Effect of evidence-based feeding guidelines on mortality of critically ill adults: a cluster randomized controlled trial. JAMA 2008, 300:2731-2741.

21. Martin CM, Doig GS, Heyland DK, Morrison T, Sibbald WJ: Multicentre, cluster-randomized clinical trial of algorithms for critical-care enteral and parenteral therapy (ACCEPT). CMAJ 2004, 170:197-204.

22. Taylor SJ, Fettes SB, Jewkes C, Nelson RJ: Prospective, randomized, controlled trial to determine the effect of early enhanced enteral nutrition on clinical outcome in mechanically ventilated patients suffering head injury. Crit Care Med 1999, 27:2525-2531.

23. Alberda C, Gramlich L, Jones N, Jeejeebhoy K, Day AG, Dhaliwal R, Heyland DK: The relationship between nutritional intake and clinical outcomes in critically ill patients: results of an international multicenter observational study. Intensive Care Med 2009, 35:1728-1737.

24. Heyland DK, Cahill NE, Dhaliwal R, Wang M, Day AG, Alenzi A, Aris F, Muscedere J, Drover JW, McClave SA: Enhanced protein-energy provision via the enteral route in critically ill patients: a single center feasibility trial of the PEP uP protocol. Crit Care 2010, 14:R78

25. Heyland DK, Cahill N, Day AG: Optimal amount of calories for critically ill patients: depends on how you slice the cake! Crit Care Med 2011, 39:2619-2626.

26. Engel C, Brunkhorst FM, Bone HG, Brunkhorst R, Gerlach H, Grond S, Gruendling M, Huhle G, Jaschinski U, John S, Mayer K, Oppert M, Olthoff D, Quintel M, Ragaller M, Rossaint R, Stuber F, Weiler N, Welte T, Bogatsch H, Hartog C, Loeffler $M$, Reinhart K: Epidemiology of sepsis in Germany: results from a national prospective multicenter study. Intensive Care Med 2007, 33:606-618.

27. Quenot JP, Binquet J, Kara F, Martinet O, Ganster F, Navellou JC, Castelain V, Barraud D, Cousson J, Louis G, Perez P, Kuteifan K, Noirot A, Badie J, Mezher C, Lessire $\mathrm{H}$, Pavon $\mathrm{A}$, group aES: The epidemiology of septic shock in French intensive care units: the prospective multicenter cohort EPISS study. Crit Care 2013, 17:R65.

28. Casaer MP, Mesotten D, Hermans G, Wouters PJ, Schetz M, Meyfroidt G, Van Cromphaut S, Ingels C, Meersseman P, Muller J, Vlasselaers D, Debaveye Y, Desmet L, Dubois J, Van Assche A, Vanderheyden S, Wilmer A, Van den Berghe G: Early versus late parenteral nutrition in critically ill adults. N Engl J Med 2011, 365:506-517. 
29. Gramlich L, Kichian K, Pinilla J, Rodych NJ, Dhaliwal R, Heyland DK: Does enteral nutrition compared to parenteral nutrition result in better outcomes in critically ill adult patients? A systematic review of the literature. Nutrition 2004, 20:843-848.

30. Heidegger CP, Berger MM, Graf S, Zingg W, Darmon P, Costanza MC, Thibault R, Pichard C: Optimisation of energy provision with supplemental parenteral nutrition in critically ill patients: a randomised controlled clinical trial. Lancet 2013, 381:385-393.

31. Krishnan JA, Parce PB, Martinez A, Diette GB, Brower RG: Caloric intake in medical ICU patients: consistency of care with guidelines and relationship to clinical outcomes. Chest 2003, 124:297-305.

32. Needham DM, Dinglas VD, Bienvenu OJ, Colantuoni E, Wozniak AW, Rice TW, Hopkins RO: One year outcomes in patients with acute lung injury randomised to initial trophic or full enteral feeding: prospective follow-up of EDEN randomised trial. BMJ 2013, 346:f1532.

33. Needham DM, Dinglas VD, Morris PE, Jackson JC, Hough CL, Mendez-Tellez PA, Wozniak AW, Colantuoni E, Ely EW, Rice TW, Hopkins RO: Physical and cognitive performance of acute lung injury patients one year after initial trophic vs full enteral feeding: EDEN trial follow-up. Am J Respir Crit Care Med 2013, 188:567-576.

34. Bedford JR, Ivermee CL, Lange K, Chapman MJ: Nutrition and functional outcomes after critical illness due to pandemic (H1N1) 2009 influenza: a retrospective cohort study. Crit Care Resusc 2011, 13:226-231.

35. Faisy C, Lerolle N, Dachraoui F, Savard JF, Abboud I, Tadie JM, Fagon JY: Impact of energy deficit calculated by a predictive method on outcome in medical patients requiring prolonged acute mechanical ventilation. Br J Nutr 2009, 101:1079-1087.

36. Heyland DK, Stephens KE, Day AG, McClave SA: The success of enteral nutrition and ICU-acquired infections: a multicenter observational study. Clin Nutr 2011, 30:148-155.

37. Rimdeika R, Gudaviciene D, Adamonis K, Barauskas G, Pavalkis D, Endzinas Z: The effectiveness of caloric value of enteral nutrition in patients with major burns. Burns 2006, 32:83-86.

38. Vincent $\mathrm{J}$ : We should abandon randomized controlled trials in the intensive care unit. Crit Care Med 2010, 38:S534-S538.

39. Benson K, Hartz AJ: A comparison of observational studies and randomized, controlled trials. N Engl J Med 1878-1886, 2000:342.

40. Concato J, Shah N, Horwitz Rl: Randomized, controlled trials, observational studies, and the hierarchy of research designs. $N$ Engl J Med 1887-1892, 2000:342.

41. Vincent $J$, Preiser JC: Are prospective cohort studies an appropriate tool to answer clinical nutrition questions? Curr Opin Clin Nutr Metab Care 2013, 16:182-186.

doi:10.1186/cc13720

Cite this article as: Elke et al:: Close to recommended caloric and protein intake by enteral nutrition is associated with better clinical outcome of critically ill septic patients: secondary analysis of a large international nutrition database. Critical Care 2014 18:R29.

\section{Submit your next manuscript to BioMed Central and take full advantage of:}

- Convenient online submission

- Thorough peer review

- No space constraints or color figure charges

- Immediate publication on acceptance

- Inclusion in PubMed, CAS, Scopus and Google Scholar

- Research which is freely available for redistribution

Submit your manuscript at www.biomedcentral.com/submit
C Biomed Central 